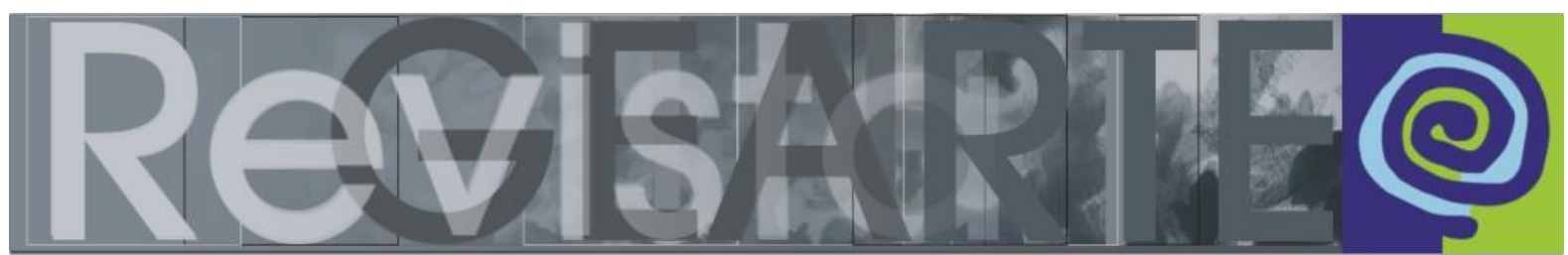

ISSN 2357-9854 | e-ISSN 2596-3198 (online)

\title{
Para escutar os ecos do legado de Noemia de Araújo Varela
}

\author{
Fernando Antônio Gonçalves de Azevedo \\ (Universidade Federal de Pernambuco — UFPE- \\ Campus Agreste, Caruaru/PE, Brasil)
}

RESUMO - Para escutar os ecos do legado de Noemia de Araújo Varela - Escutar os ecos do legado de Noemia de Araújo Varela exige um olhar questionador para a História da Arte/Educação, reconhecendo o papel singular das mulheres nesse campo de ensino, aprendizagens e pesquisas. Nesse sentido, o presente ensaio destaca aspectos do pensamento noemiano por meio do fragmento de uma entrevista reveladora de seus pensares e fazeres.

\section{PALAVRAS-CHAVE}

História da Arte/Educação. Fazeres e Pensares. Legado de Noemia Varela.

ABSTRACT - To listen to the echoes of the Noemia de Araújo Varela's legacy - Listen to the echoes of the Noemia de Araújo Varela's legacy demands a questioner look for the History of Art / Education, recognizing the singular paper of the women in this field of education, learning and research. In this sense, the present essay highlights aspects of the Noemiano thought through of the fragment of a revealing interview of her thoughts and actions.

\section{KEYWORDS}

History of Art / Education. Thoughts and Actions. Legacy of Noemia Varela.

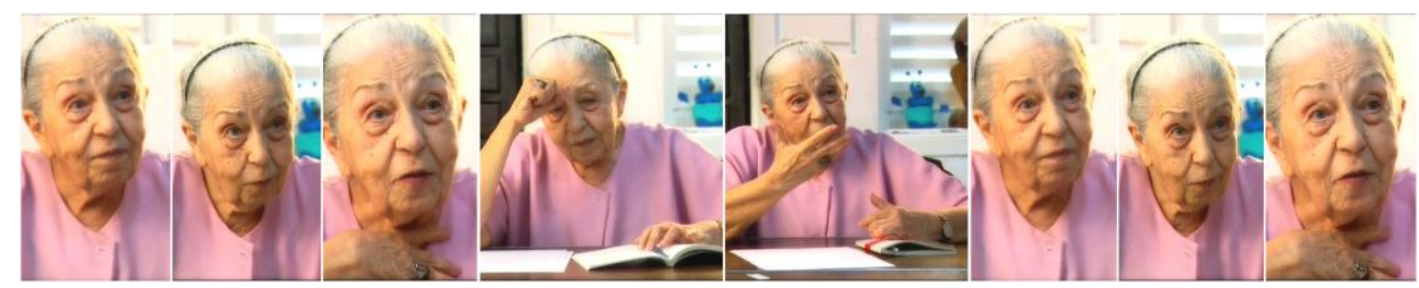

Por que arte/educação?, perguntou-me uma das avaliadoras durante a entrevista de seleção para o mestrado em Educação na UFRGS. Não recordo ao certo o que respondi, porém, essa indagação tem me acompanhado desde então - acredito que persistirá por alguns anos, como um farol que ajuda a orientar o marinheiro em sua jornada. Percebo-me como uma pesquisadora iniciante que navega em mares desconhecidos e assustadoramente encantadores. Mais do que a chegada, o percurso é o que motiva, pois nas aventuras e desventuras do conhecimento somos eternos aprendizes (ALVES, 2019, p. 16).

\section{... a história como busca de descolonizar narrativas...}

Ao se dizer iniciante no campo da Arteducação, Flávia Alves cria a metáfora do marinheiro navegando, guiado pelo farol, em mares desconhecidos, mas encantadores. Essa é uma bela imagem, criada pela autora, para se dizer 


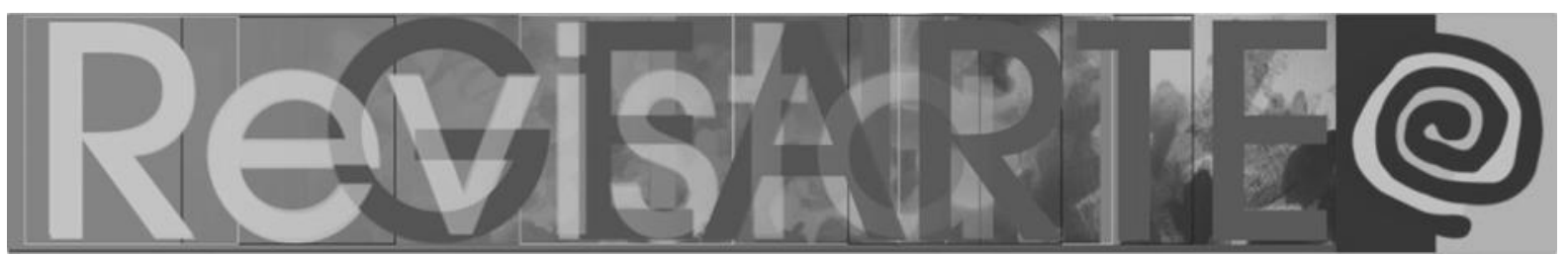

arteducadora/pesquisadora... e dizer, a seu modo, que o gesto de pesquisar é uma experiência de recriação, que exige espírito de aventura. Não basta seguir as rotas que outros pesquisadores já trilharam, é necessário mais que isso, pois cada universo que pesquisamos, pode ser interpretado por um ângulo de visão próprio, e é esse ângulo especial, que nos leva à criação de nossa própria rota, lidando com a incerteza.

No início de seu texto, Flávia Alves cita Peter Burke afirmando uma postura muito importante do pesquisador em História - e incorporada pela autora ao gesto de pesquisar em História da Arteducação:

[...] cada vez mais historiadores estão começando a perceber que seu trabalho não reproduz "o que realmente aconteceu", tanto quanto o representa de um ponto de vista particular. Para comunicar essa consciência aos leitores de história, as formas tradicionais de narrativa são inadequadas. Os narradores históricos necessitam encontrar um modo de se tornarem visíveis em sua narrativa, não de autoindulgência, mas advertindo o leitor de que eles não são oniscientes ou imparciais e que outras interpretações, além das suas, são possíveis (2011, p. 345). (grifo do autor).

No fragmento em destaque, a ideia de que o pesquisador em História não "reproduz o que realmente aconteceu", por não conseguir ser onisciente (construir um saber pleno e absoluto sobre as coisas e os fatos) e imparcial (ter julgamento isento de paixão), refere-se à compreensão de que o historiador, dentre outros, recria uma narrativa sobre um determinado acontecimento histórico, e essa pode ser pensada como um ponto de vista possível, mas nunca como a verdade absoluta.

Tal posicionamento de Burke impõe uma reflexão sobre o sentido das palavras: reproduzir e recriar. Reproduzir, aproximadamente, é fazer uma cópia a mais perfeita possível de algo, enquanto recriar exige interpretação, exige estudos, gera a criação de hipóteses e afirma-se como incompleta, pois aberta, o que levou-me ao pensamento da analista de discurso Eni Orlandi (2011, p. 33), mais precisamente, à sua noção de Sujeito:

Seria oportuno fazer, [...], uma observação a respeito da noção de sujeito. Como considero que a apropriação da linguagem é construída socialmente, esse sujeito do qual falo não é, pois, o sujeito em-si, abstrato e ideal, mas o sujeito mergulhado no social que o envolve, e preso, pois, da contradição que o constitui. 


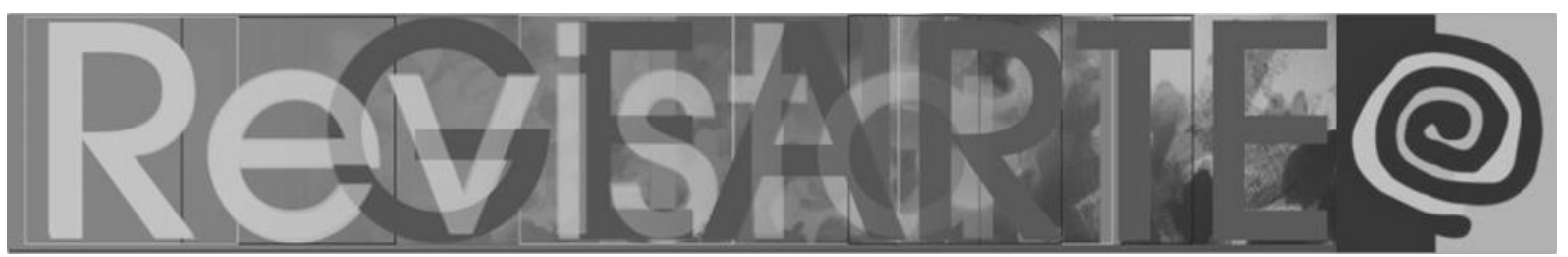

Tal compreensão de sujeito, mergulhado e envolvido no social, colhida do pensamento de Orlandi, pode ser posta em diálogo com a noção de sujeito não onisciente e não imparcial de Burke. Cada autor - refiro-me ao próprio Burke (2011) e a Orlandi (2011) - a seu modo, chama a nossa atenção para o fato de sermos seres incompletos, pois enredados em contradições.

O historiador, portanto, não escapa da incompletude humana, por isso seu trabalho de interpretar a história pode ser pensado como uma recriação. Afinal, o historiador não é o dono da verdade, pois seu modo de narrar a história é apenas uma interpretação, dentre outras, sobre um determinado acontecimento.

Pensando o historiador como um recriador de narrativas e não um mero reprodutor, propomos uma parada no campo da Filosofia. Entra em cena o pensamento de Franklin Leopoldo e Silva (2011, p. 9), dizendo: “O 'espanto' diante das coisas, do qual falam Platão e Aristóteles como sendo a causa inicial da filosofia, isto é, do saber, é, antes de tudo, um modo de se pôr diante do mundo."

Valendo-me do que afirma Leopoldo e Silva, retomando Platão e Aristóteles, ouso dizer que o gesto de pesquisar é um modo de se pôr diante do mundo, que nos faz recordar os pré-socráticos, em suas buscas de atribuir sentidos para o mundo, o trabalho de criação dos artistas e cientistas de todas as épocas, e dos místicos, em suas buscas de desvelar o mistério. Faz-me recordar, em especial, o documentário de Werner Herzog, "A Caverna dos Sonhos Esquecidos" (2011), por ser esse filme um convite, muito respeitoso, a um mergulho na história.

Mas, antes de voltar à obra de Herzog, destaco: compreendo a pesquisa de Flávia Alves como um modo de se pôr diante do mundo e essa (pesquisa) por ter como tema a Escolinha de Arte da UFRGS, remeteu-me aos pensares e fazeres de Noemia de Araújo Varela (1917-2016) - pioneira do campo da Arteducação de nosso país. Na verdade, remeteu-me ao trabalho de pesquisa que desenvolvi no Curso de Mestrado em Artes, intitulado: "Movimento Escolinhas de Arte: em cena memórias de Noemia Varela e Ana Mae Barbosa", orientado pela Dra Regina Machado na ECA-USP. 


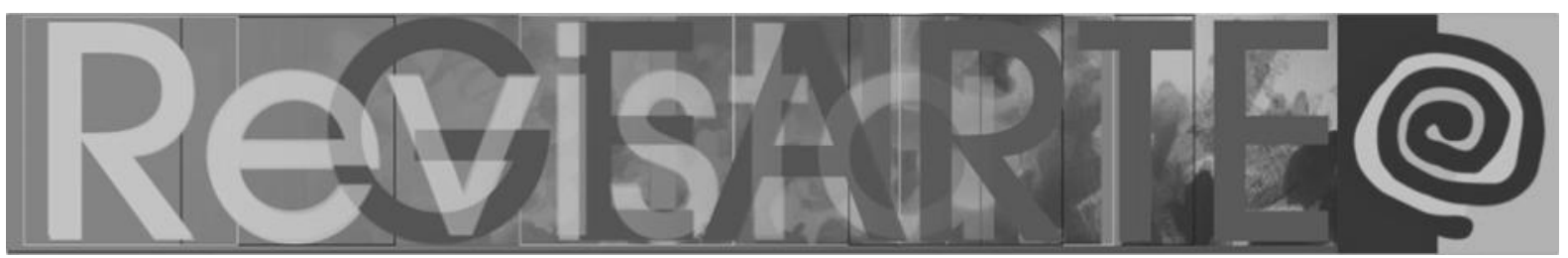

Naquele momento, busquei inscrever as memórias das duas arteducadoras na dissertação. Sonhava, porém, gravar em vídeo, fragmentos das memórias de uma e de outra. O que significaria, a um só tempo, a palavra e imagem sincronizadas, para que elas narrassem suas memórias e histórias, dirigindo-se às novas gerações de arteducadores.

Mais tarde, consegui elaborar, em vídeo, uma entrevista com Dona Noemia, para compor a exposição - "Noemia Varela: uma vida, fazeres e pensares" (https://www.youtube.com/watch?v=uo6vmtCovFw). Essa exposição foi em homenagem aos 90 anos de Dona Noemia. E depois realizei, com o apoio da Fundação Joaquim Nabuco, a entrevista-vídeo - "Ana Mae Barbosa: fragmentos de um discurso de amor à Arte/Educação". Esse vídeo foi distribuído aos arteducadores de escolas públicas e de universidades, pela FUNDAJ, e posteriormente no Confaeb de 2012, sediado na UNESP, em São Paulo, a Fundação distribuiu aos participantes, especialmente para aqueles representantes de Secretarias de Educação, Universidades e intuições culturais. Uma curiosidade sobre as duas entrevistas-vídeos é que essas foram filmadas na Escolinha de Arte do Recife, na mesma sala, por escolha das arteducadoras.

Atualmente, posso dizer que, tanto o Movimento Escolinhas de Arte, quanto a busca incansável de Noemia Varela em constituir-se arteducadora, tornaram-se temas de pesquisa para mim, desde meados dos anos de 1990. Época em que desfrutei do privilégio de conviver com Dona Noemia, como aprendiz de arteducador, pois nessa época ela voltou a morar em Recife.

Em sua lida para manter viva a Escolinha de Arte do Recife, promoveu (nessa época) cursos, exposições e debates. Sabia, como poucas, criar um clima de estudos nesses eventos, por ter profundo respeito pelo modo de pensar do Outro. O que não significava calar-se passivamente frente à posição de seus interlocutores, mas buscava sempre, por meio da reflexão, possibilitar o debate. 


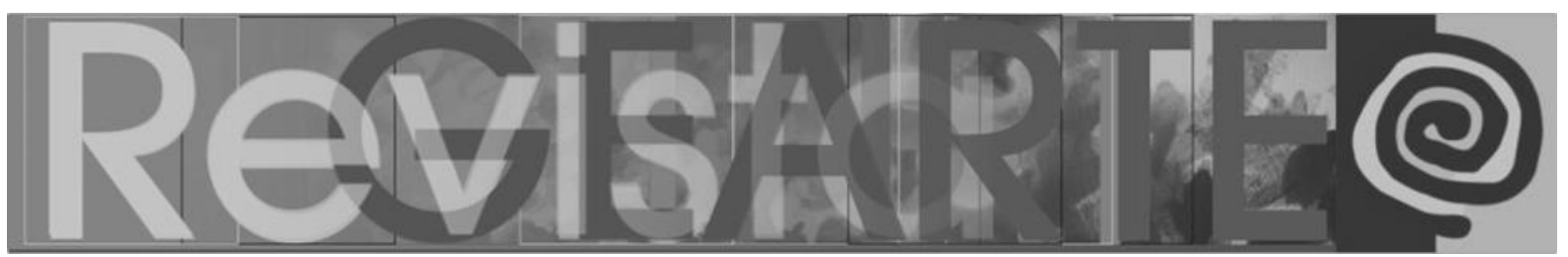

Por essas razões, afirmo: não é fruto de uma mera casualidade o fato de ter escolhido a epígrafe, para abrir este ensaio, no texto da pesquisa de Flávia Alves, pois ela foi orientanda de Analice Dutra Pillar (UFRGS), que por sua vez foi orientanda (Mestrado e Doutorado) de Ana Mae Barbosa (ECA-USP). E, Ana Mae Barbosa dizse filha intelectual de Noemia de Araújo Varela. Aqui, temos, portanto, uma evidência dos pensares e fazeres de Dona Noemia, como um legado, que possui variadas possibilidades de interpretação - daí sua riqueza...

Arrebatado, pois, pelo belo trabalho de pesquisa de Flávia Alves, resolvi retomar, reabrir e apresentar neste ensaio fragmentos muito significativos de uma entrevista que fiz com Noemia de Araújo Varela - Mestra-Mater da Arteducação brasileira (ou Dona Noemia, como aprendemos a nomeá-la com Ana Mae Barbosa em sinal de reverência). Novamente, o local da entrevista foi a Escolinha de Arte do Recife, escolha da própria Dona Noemia.

Volto, então, ao filme "A Caverna dos Sonhos Esquecidos" de Herzog, pois depois de ver e rever, profundamente encantado o referido documentário, passei a intuir que a Escolinha de Arte do Recife era, para Dona Noemia, no sentido histórico e antropológico, guardando, talvez, as devidas proporções, o que representa a Caverna de Chauvet, localizada em território francês, para o cineasta. Ambos, o cineasta e a arteducadora, apaixonados pela Arte e pelas marcas de nossos ancestrais na história. Ela, falando das memórias do Movimento Escolinhas de Arte paixão que transformou sua história pessoal-profissional - fato que torna muito difícil falar da pessoa - Dona Noemia - sem recorrer à arteducadora. Ele, nesse filme especialmente, gravando as impressões de nossos ancestrais inscritas, há mais de 30 mil anos, nas paredes da Caverna Chauvet - verdadeiro presente para a humanidade em geral e, muito especialmente, para a história das culturas.

Há uma passagem no documentário-arte em que Herzog convida sua pequena equipe ao SILÊNCIO, ao silêncio como uma reverência a nossa própria ancestralidade... dizendo assim: - "Silêncio, por favor...vamos ouvir a Caverna e ...Talvez, possamos ouvir as batidas de nosso coração...". 


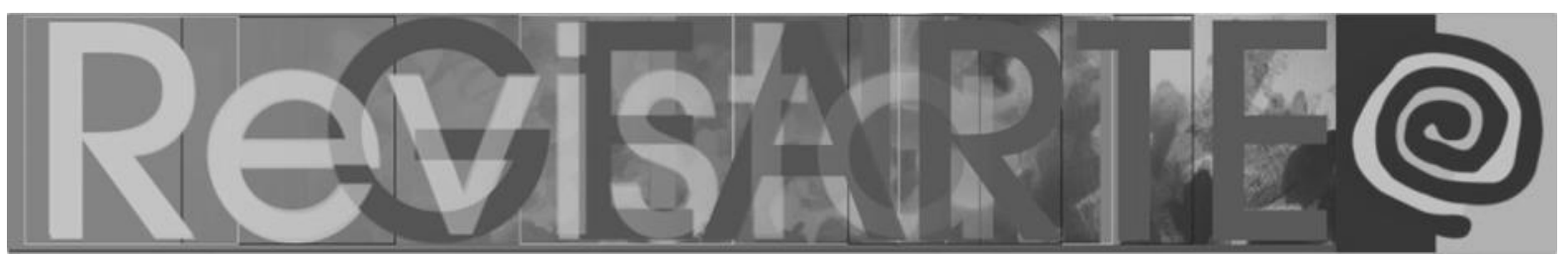

A solicitação de uma atitude de silêncio, por respeito à história desenhada na caverna, como evidencia o texto do cineasta, é complementada sabiamente pela suposição: "Talvez, possamos ouvir as batidas de nosso coração”. E este é um convite que Herzog faz, também, aos leitores do filme. Quiçá a toda a humanidade... convite, que talvez possa ser interpretado como um alerta à surdez generalizada em que vivemos, isto é, a nossa surdez quanto à "voz" da própria Terra - ser vivo, a casaorganismo em que vivemos...surdez e cegueira com relação às nossas próprias histórias...Espanto? ...

Volto ao trabalho de Flávia Alves, intitulado: "Escolinha de Arte da UFRGS (1960-2011): história, fundamentos e ressonâncias com o Movimento Escolinhas de Arte", pois esse trabalho pode ser interpretado como um convite a esse silêncioreverência de que fala o cineasta. De certo modo - Flávia convida seu leitor a silenciar - para escutar com maior profundidade os ecos das alegrias, dos sonhos, dos medos e das paixões daquelas e daqueles que semearam (e semeiam com suas memórias) o campo da Arteducação...

Aqui, um aviso é necessário: esta seção, construída como uma espécie de introdução, um tanto quanto longa, foi sendo elaborada e alimentada pelos angustiantes impasses entre o pensamento colonialista e o pós-colonialista. Para tanto, busquei articular dois fragmentos de pensamento, que colocados em diálogo, dizem de minha busca de interpretar as memórias-discursos de Dona Noemia. De Ecléa Bosi (2003, p. 65), de quem fui aluno no mestrado, ressalto: "A fala emotiva e fragmentada é portadora de significações que nos aproximam da verdade. Aprendemos a amar esse discurso tateante, suas pausas, suas franjas com fios perdidos quase irreparáveis." E de Eni Orlandi (2007, p. 58), destaco:

\footnotetext{
Observar os fatos de linguagem vem a ser considerá-los em sua historicidade, enquanto eles representam um lugar de entrada na memória da linguagem, [...] olharmos o texto como fato, e não como dado, e observarmos como ele, enquanto objeto simbólico, funciona.
}

Sabendo, pois, que o silêncio, o não-dito e a emoção contida são marcas da memória-discurso que significam...ANUNCIO: 


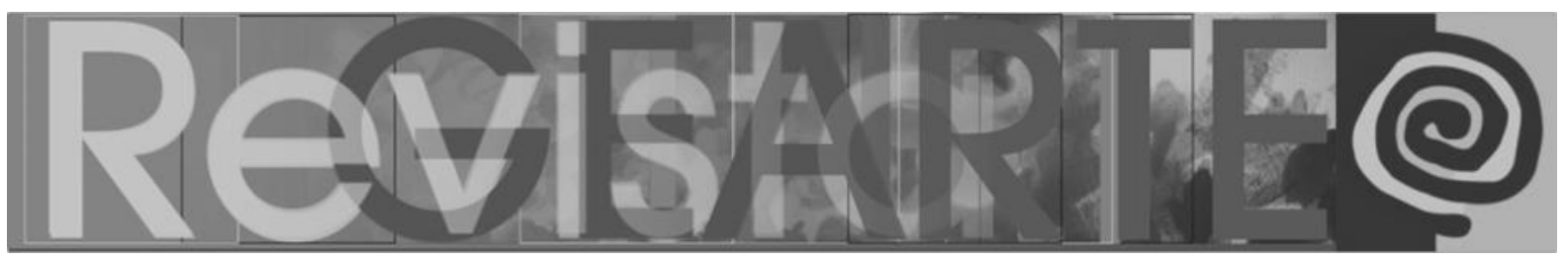

\section{Com a palavra Noemia de Araújo Varela}

O silêncio solicitado por Herzog à sua equipe, diante da história inscrita na caverna, levou-me a "escutar" Dona Noemia, não seguindo a lógica da entrevista. Deixei-me guiar pelas batidas de meu coração e revivi com prazer a determinação de Dona Noemia em buscar sua história pelo gesto de relembrar. Escolhi, dessas lembranças, apenas duas questões, à luz de estudos que venho realizando atualmente.

E faço isso, considerando que a pesquisa em história da Arteducação aponta para a descolonização dos conhecimentos e saberes, especialmente porque, neste caso, o papel singular das mulheres é marcante. Faz-se necessário, por isso, escutar os ecos do Legado Noemiano - escutar para refletir sobre, para apreender, para ousar recriar...

Começo com um dos trechos que mais me emociona e que se traduz como uma marca do legado noemiano: olhar para o Outro, o diferente, não pelo ângulo de suas deficiências, mas pelo ângulo de suas potencialidades. Esse é para mim o princípio mais descolonizador que apreendi com nossa Mestra-Mater.

A resposta de Dona Noemia, a seguir, refere-se à sua volta para a Escola Ulisses Pernambucano, depois do impacto que havia tido ao conhecer a Escolinha de Arte do Brasil (em 1949), criada, segundo ela, por Augusto Rodrigues, Lúcia Alencastro Valentim e Margaret Spencer, no Rio de Janeiro, em 1948.

Eis, as questões e os comentários....

FA $^{1}$ - Logo depois que a senhora conheceu a Escolinha de Arte do Brasil criou o Atelier de Arte na Escola Ulisses Pernambucano?

\footnotetext{
Fernando Azevedo.
} 


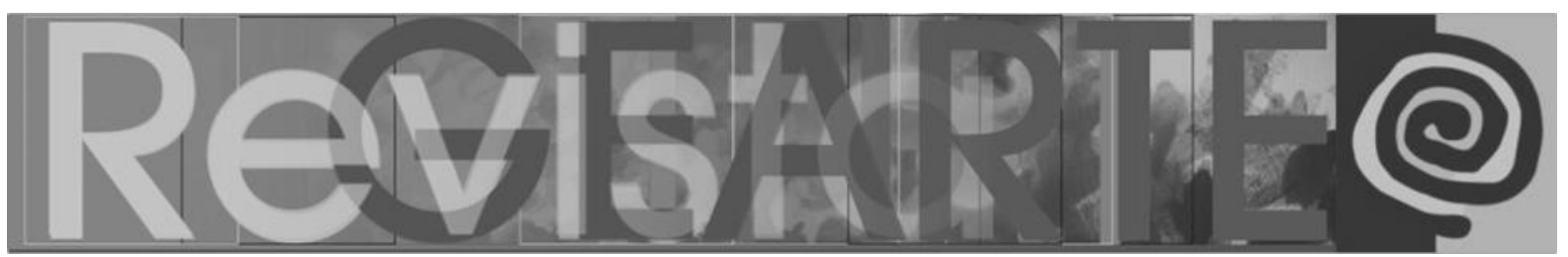

$\mathbf{N V}^{2}$ - Esse atelier era frequentado entre a hora do recreio até a hora da saída, mais ou menos até dez para o meio dia, ele funcionava... quinze para o meio dia, tocava a sineta para se arrumar e eles trabalhavam cerca de uma hora, uma hora e dez, não muito mais. Vinha quem queria. Ninguém era obrigado. Era livre a frequência, mas nunca deixei de ter aluno. Aprendi coisas maravilhosas, porque havia um grupo de crianças que o Dr. Rodolfo Aureliano mandava do juizado de menores [formado em Ciências Jurídicas e Sociais, Rodolfo Aureliano, trabalhou voltado para as crianças e jovens abandonados socialmente, esse fato de sua história fez com que nomeassem uma escola com seu nome, no bairro da Várzea em Recife - Escola Municipal Doutor Rodolfo Aureliano].

Entre essas crianças havia epilépticos. Havia um que tinha constantes convulsões e eu me lembro que ele ficava com um pincel na mão... eram rápidas as ausências. [...] ... e tinha um outro que sempre me dizia: "Espere Dona Noemia! .... Espere, que vai passar.... Espere! ". E eu fui aprendendo como existia solidariedade entre eles ... Havia uma história, entre aspas, de pavor de ir para a Escola Ulisses Pernambucano, que chamavam "Escola de Loucos" e por isso era muito temida [na realidade houve uma época, contava Dona Noemia, que a Escola Ulisses Pernambucano era nomeada de Escola de Crianças Anormais]. Mas, também, temiam aquelas crianças, embora elas precisassem muito de quem gostasse delas, as amasse... e como havia bondade, havia vontade de acertar. Eu não sabia o que é que eu estava fazendo e muitas de nós ali, não sabíamos, não é? Eram ensaios e erros. Não havia livros mostrando o que era a Arte da criança, o mais atualizado [na época] era Psicologia do Desenho (1935) de Sylvio Rabello, aliás eu disse muita coisa sobre esse livro a Rejane [Referindo-se a Rejane Galvão Coutinho - UNESP - e sua dissertação de Mestrado sobre Sylvio Rabello, orientada por Ana Mae Barbosa, na ECA/USP], na pesquisa dela sobre Sylvio Rabello. É, mas assim mesmo não dava. Os livros... eram livros antigos, não tinha material. Eu escrevi para Lúcia Valentim, escrevi para Augusto Rodrigues, perguntando [...]. Eu não manejava tinta e pincel.

Noemia Varela.

AZEVEDO, Fernando Antônio Gonçalves de. Para escutar os ecos do legado de Noemia de Araújo Varela. 459 Revista GEARTE, Porto Alegre, v. 6, n. 2, p. 452-467, maio/ago. 2019.

Disponível em: http://seer.ufrgs.br/gearte 


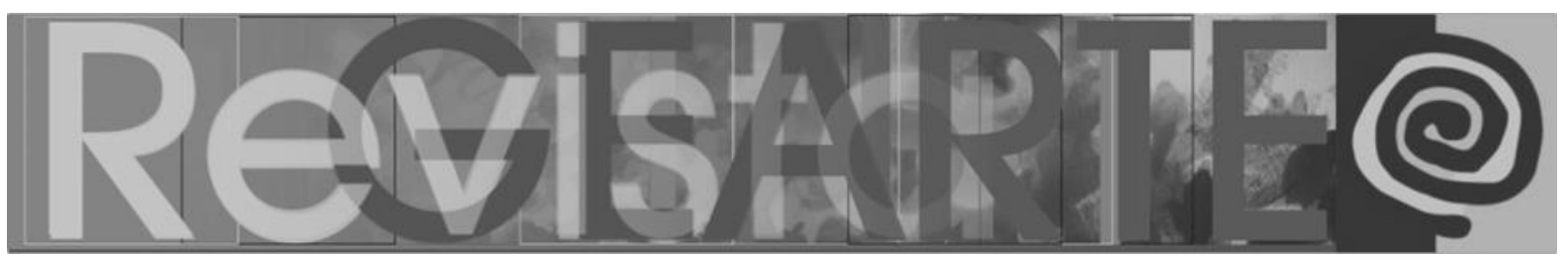

[...]. Lembrei das brincadeiras de fazer arte da minha adolescência, dos meus rabiscos. Aprendi a primeira grande lição: não posso acreditar em professor de arte que não tenha vivido a experiência do ato de criar, é fundamental esse encontro...

\title{
Comentário...
}

Fui compreendendo, no convívio com Dona Noemia, que o "ato criador" é algo que mobiliza a imaginação, mas, necessariamente não precisa materializar-se em uma obra ou em um objeto de arte, ou seja, esse traduz-se em uma atitude, isto é, um modo de Ser e Estar no Mundo, atitude marcada pela articulação entre as dimensões ética e estética, como de certo modo, expressa sua resposta reflexiva.

A partir dos estudos do pensamento de Michel Foucault, mais enfaticamente da ideia de Vida Artista, interpreto que o que Dona Noemia compreende como ato criador é na verdade um modo de olhar para si, para o Outro e para o Mundo de uma perspectiva estética e ética. Gesto que, em muito se aproxima da ideia de estética da existência, isto é, da capacidade de nos tornamos artesãos-artistas construtores de nossa própria vida. Nesse sentido, Guilherme Castelo Branco, um dos filósofos brasileiros estudioso de Foucault, diz:

\begin{abstract}
Michel Foucault faz questão de sustentar uma hipótese exatamente contraria à da teoria do artista inspirado, de maneira a não deixar qualquer dúvida. $O$ filósofo francês afirma que a estética da existência, enquanto atitude pela qual nos tornamos artífices da beleza de nossa própria vida, é um estilo de vida de alcance comunitário, por ele também denominado de modo de vida "artista", realizável por todo aquele que seja capaz de questionamento ético, e que ademais seja, em alguma medida, capaz de realizar uma "atitude de modernidade". (2009, p. 143)
\end{abstract}

Depois de alguns anos, reler essa entrevista, leva-me a intuir que o que Dona Noemia chama de "ato criador", de certa maneira, pode ser compreendido, a partir da ótica foucaultiana como Vida Artista, pois nossa Mestra-Mater foi artífice da beleza do gesto de arteducar pessoas que viviam à margem. E fazia isso com o olhar voltado para as potencialidades das pessoas - um bom exemplo é a relação que manteve com o menino epilético e o seu amigo. $O$ diálogo entre ela e o amigo do menino epilético traduz seu respeito ao Outro. Além disso, essa resposta-reflexiva traduz algo 


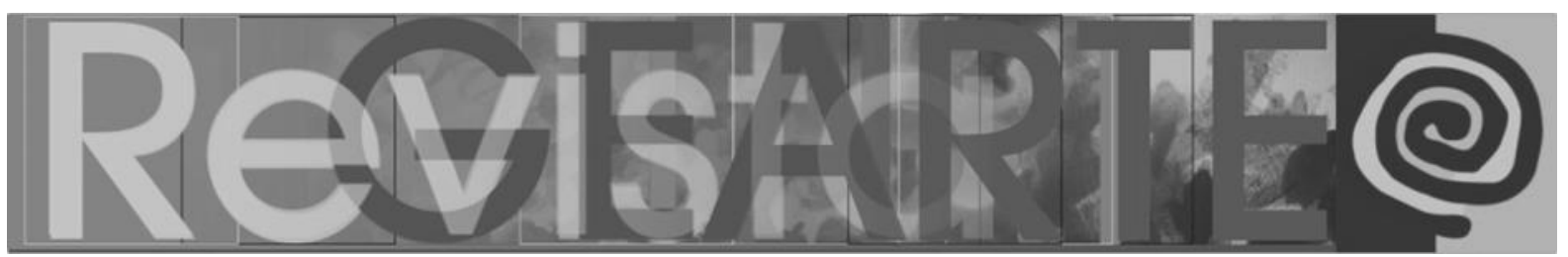

muito profundo: ela tinha consciência de sua incompletude. Dona Noemia queria saber mais, aprender e apreender sobre o gesto de arteducar. Seu modo, pois, de olhar para a Vida e para a Arteducação era filosófico, porque carregado de questionamentos e alimentado constantemente pela reflexão.

A perspectiva de olhar para o Outro, buscando suas potencialidades, é, em minha compreensão, a busca de criar maneiras de descolonizar os processos de ensino e de aprendizagem da Arte. Dona Noemia, nesse sentido, instaurou uma epistemologia que partia do seguinte princípio: cada pessoa traz em si potencialidades para apreender os conhecimentos. O papel do arteducador é buscar a potencialidade do estudante e não simplesmente enclausurá-lo em sua incompletude ou deficiência. Assim, o arteducador pode se fortalecer e buscar alternativas para abandonar as epistemologias colonizadoras, que instituem quem é capaz de aprender e quem não tem chance, ou seja, epistemologias que partem de um modelo de normalidade excludente.

Foi isso que ela fez, por exemplo, no Atelier de Artes da Escola Ulisses Pernambucano. Não é por acaso, que mais tarde, morando no Rio de Janeiro, tenha dedicado-se aos estudos do pensamento de Carl Gustav Jung (1875-1961), participando do Grupo de Estudos Jungianos, criado pela Doutora Nise da Silveira.

Lembro muito bem de Dona Noemia, em seus cursos e palestras, na Escolinha de Arte do Recife, apresentando diversos estudos de caso (elaborados por ela), sobre pessoas com sofrimentos mentais, todos esses baseados na psicologia de Jung. Uma curiosidade, nesse sentido, é muito importante destacar: esses estudos foram orientados pela própria Doutora Nise da Silveira e por outras pessoas que participavam do Grupo.

Depois de seu falecimento, tentei resgatar alguns desses estudos, junto com Cleonice Regis, sua grande colaboradora na Escolinha de Arte do Recife. O pouco material que consegui, nessa ocasião, encontra-se no ensaio, "Noemia Varela - um Réquiem para (NÃO) dizer (A) DEUS", no livro Mulheres Não Devem Ficar em 


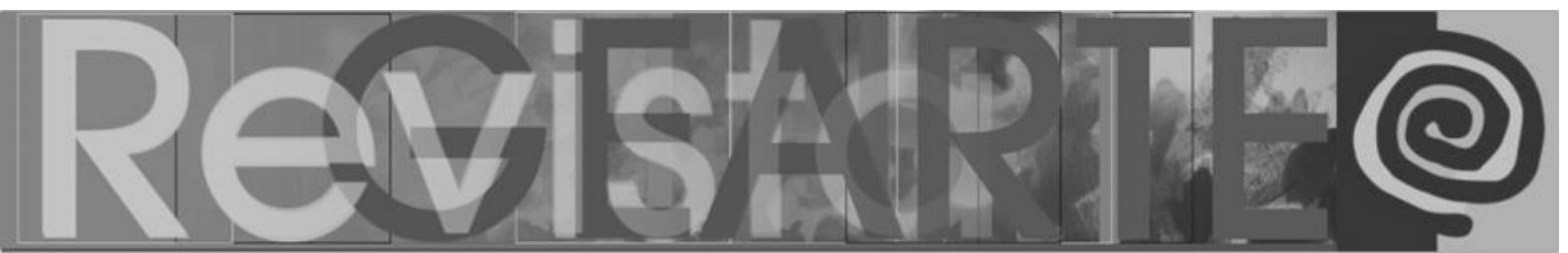

Silêncio: Arte, Design, Educação, que foi publicado em 2019 pela editora Cortez, organizado por Ana Mae Barbosa e Vitoria Amaral.

De certo modo, a próxima resposta de Dona Noemia traz mais ideias sobre o "ato criador", pois ela cita um aspecto do pensamento de Herbert Read, autor inglês estudioso de Jung, que muito influenciou o Movimento Escolinhas de Arte.

FA - Hoje [1998] há uma crítica ao Movimento Escolinhas de Arte, especialmente em relação às Artes Plásticas, quanto à tentativa de preservar a criança do contato com a obra de arte. Considerando que esse contato poderia levar a criança para o caminho da cópia. Como é que a senhora analisa esta crítica?

NV - Eu mostrei a você o quanto Herbert Read influenciou o Movimento Escolinhas de Arte. Já fiz isso várias vezes. Tenho falado e acho que foi uma experiência muito rica, positiva. Ele achava que não se devia levar a criança à imitação, porque a postura da criança diante da Arte não era de uma concentração para fazer um trabalho artístico, um trabalho como artistas fazem. Então, [provavelmente Dona Noemia fala, aqui, da ideia de Livre-Expressão] o fazer arte da criança vem de dentro, é uma capacidade inata, a capacidade inata da criança expressar sentimentos, sensações. A imaginação da criança tem uma pureza, uma transparência. É aquilo que Matisse falava o tempo todo: há uma coesão de pensamento, mas ele sabia o que dizia. Herbert Read, no seu livro A Educação pela Arte (1982), em um texto sobre educação estética [Capítulo V, "A Arte das Crianças"], mostra a importância de se respeitar essa forma peculiar da criança, mas se a criança queria copiar, copiava. Era uma experiência que ele fazia com as crianças...

Agora, Augusto Rodrigues, tinha a ideia de não levar as crianças para ver quadros. Muitos alunos da Escolinha eram filhos de pessoas que viviam muito bem de vida e que em suas casas havia coleção de Arte: quadros de Portinari, de grandes artistas brasileiros e de artistas internacionais. Os próprios filhos de Augusto tinham, pelas paredes de sua casa, desenhos e retratos elaborados por ele e por outros artistas. Na convivência com o trabalho do adulto, as crianças viam que essa 


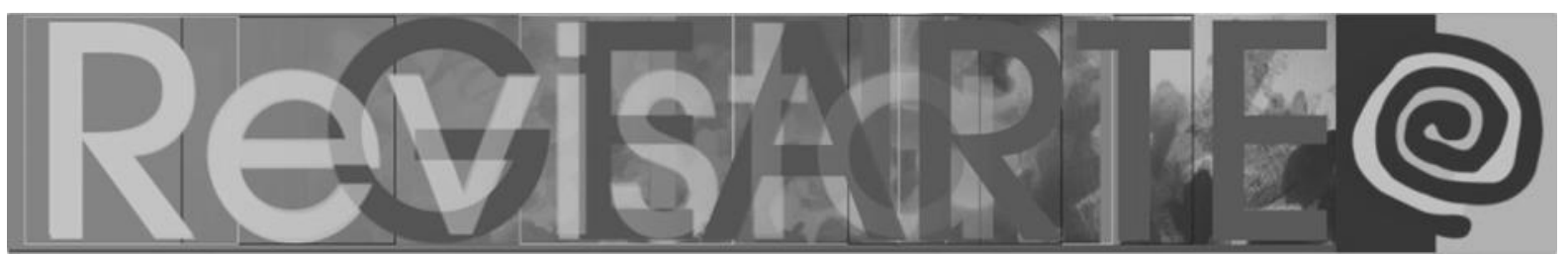

Escolinha [referindo-se à Escolinha de Arte do Brasil-RJ] recebia diariamente visita de artistas, levando seus quadros e mostrando-os ao Augusto em seu gabinete... e as crianças passavam e olhavam aquilo tudo ali exposto. Então, as crianças conviviam com os livros de Arte e os professores tinham o cuidado de levar a criança para ver coisas novas. Por exemplo, eu fui uma grande admiradora de Viktor Lowenfeld, especialmente daquele livro famoso dele [Dona Noemia cita aqui a obra Desenvolvimento da Capacidade Criadora, de autoria de Victor Lowenfeld e William L. Brittain].

Muitos pensavam que a gente podia fazer a leitura do livro e levar a criança a se desenvolver, seguindo os estágios de desenvolvimento do desenho. [...]. Lowenfeld dá um exemplo que quando um menino queria desenhar uma escada e não sabia, ele dizia: "desenhe a escada como se você estivesse subindo uma". E fazia a criança subir uma escada para experimentar sentir a escada. Quando o menino desenhava uma boca sem dentes, ele colocava uma maçã, um pedaço de pão ou qualquer outra coisa na boca da criança e fazia ela sentir como era o movimento, os dentes, a língua. Também fazia isso com deficientes mentais [penso que Dona Noemia quis dizer: deficientes visuais, pois Lowenfeld iniciou seu trabalho de Arteducação, ainda em Viena, com crianças e jovens cegos]. Havia um desabrochar, um desenvolvimento comportamental. Então eu ficava preocupada, pensando nas dificuldades de se compreender essas coisas dentro da própria escola, pois essa forma de agir não se tinha na escola.... [Dona Noemia para um pouco e busca na memória].... Eu fiz observação de classes na Inglaterra e o pensamento de Herbert Read era fundamental para os ingleses. Lá, partiam de suas ideias, mas todas as crianças tinham livro de Arte dentro da própria sala de aula, e olhavam os desenhos. Então, eu fui compreendendo que havia uma preocupação em educar a criança para lidar com o desenho... [Dona Noemia então sugere que eu estude o V Capitulo de Educação pela Arte de Read].... Não é forçar a criança a partir do que faz o artista e sim levar naturalmente a criança a compreender que existe $o$ artista e que esse elabora a obra de arte de sua maneira e que ela [a criança] pode fazer da sua própria forma. É isso que o Movimento Escolinhas de Arte propunha... é isso que a Escolinha de Arte do 


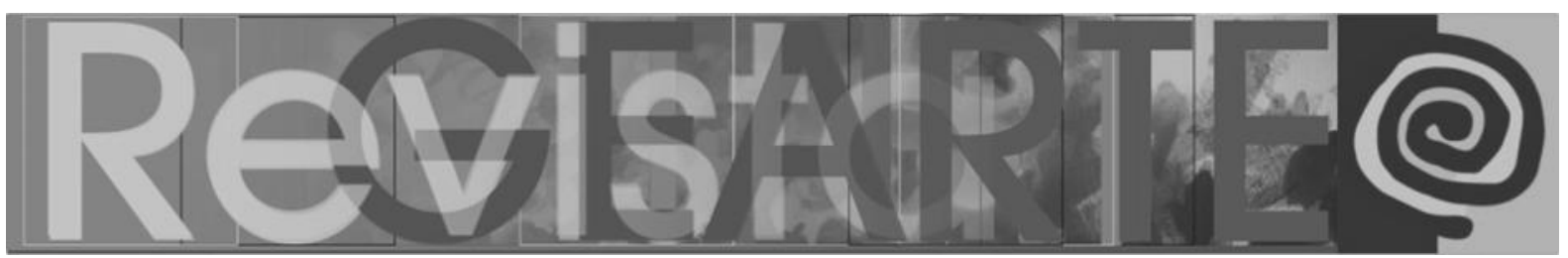

Recife faz... São sutilezas de uma preocupação que na época era comum. Na França se fazia a mesma coisa, onde a criança não via nada, para não imitar.

\title{
Comentário...
}

O que chama a minha atenção nessa resposta de Dona Noemia é algo que, na época do mestrado, não dei a devida importância, mas, hoje, percebo como algo muito significativo. Apesar de todo respeito e valorização do pensamento de Herbert Read e Viktor Lowenfeld - bases filosóficas do Movimento Escolinhas de Arte, como sempre defendeu Dona Noemia - quem tinha a última palavra, pelo menos na Escolinha de Arte do Brasil, era Augusto Rodrigues. Observem o que diz Dona Noemia, depois de fazer uma justificativa teórica e filosófica baseada em Read e Lowenfeld: "Agora, Augusto Rodrigues tinha a ideia de não levar as crianças para ver quadros".

O trecho, que Dona Noemia recomendou a leitura foi, da famosa obra de Read: Educação pela Arte (1982, p. 254), que tem como subtítulo: "O critério estético" e se inicia assim:

\begin{abstract}
Antes de nos determos nos métodos de educação que melhor se adaptam aos factos até agora descritos neste livro, temos de discutir sumariamente um aspecto preliminar que se prende com os valores. Vimos anteriormente que alguns 'desenhos livres' das crianças foram classificados de 'feios', 'horríveis', 'monstruosos' e 'anárquicos' nada menos que por uma autoridade como a $\mathrm{Dr}^{\mathrm{a}}$ Montessori. Estes desenhos 'mostram apenas que o olhar da criança não está educado, que a mão se encontra inerte, que a mente é insensível de igual modo ao belo e ao feio, cega tanto ao verdadeiro como ao falso".
\end{abstract}

Nesse trecho, Read, por sua vez, indica ao leitor voltar em páginas anteriores (1982, p. 141-142). Obedeci. O subtítulo é: "Montessori sobre a expressão espontânea". Read, cita textualmente: MONTESSORI, M. The Advanced Montessori Method. Londres, 1918, vol. II, p. 304-306. E desse fragmento colhi:

[...] a menos que saibamos como uma criança se deve desenvolver a fim de revelar as suas energias naturais, não saberemos como se desenvolve o desenho como expressão natural. O desenvolvimento universal da linguagem assombrosa da mão não surgirá de uma "escola de desenho", mas de uma "escola do homem novo" que fará com que esta linguagem surja espontaneamente como a água de uma fonte inesgotável. Para dar o dom do desenho devemos criar uma vista que vê, uma mão que obedece, uma alma que sente; e nesta tarefa deve cooperar toda a vida. Neste sentido a própria 


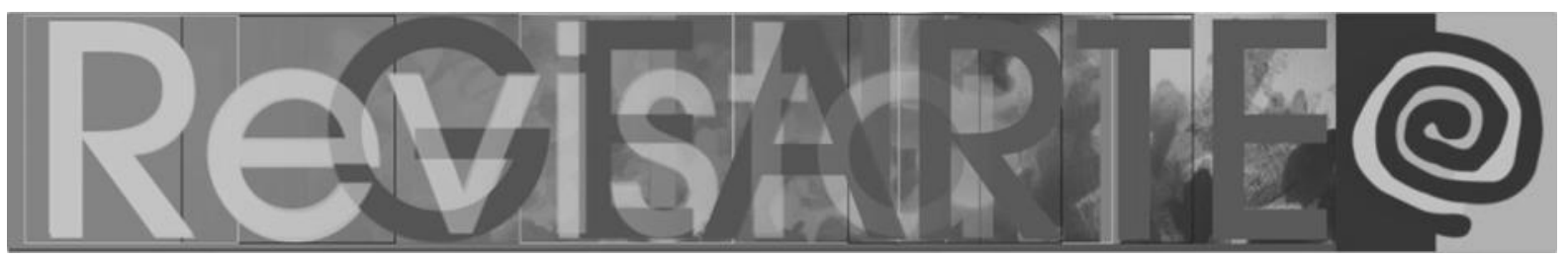

vida é a única preparação para o desenho. Uma vez que tenhamos vivido, a centelha interior fará o resto.

$\mathrm{O}$ argumento que Read construiu para analisar o pensamento da $\mathrm{Dr}^{\mathrm{a}}$ Montessori é muito significativo, pois ele chama a nossa atenção para ênfases da Arteducação Modernista, que foram incorporadas às epistemologias pós-modernistas. Observem, em foco, este trecho da citação anterior: "Estes desenhos 'mostram apenas que o olhar da criança não está educado, que a mão se encontra inerte, que a mente é insensível de igual modo ao belo e ao feio, cega tanto ao verdadeiro como ao falso".

Tal argumento, em minha compreensão, mais do que sugere, que a criança pode ser educada para ver Arte, e que isso amplia sua mente e leva ao discernimento entre o feio e o belo (discernimento estético) e entre o verdadeiro e $\circ$ falso (discernimento ético). Em outras palavras: Read defende a importância da Arte na formação do ser humano para ver a Arte reconhecida historicamente.

Um detalhe importante sobre Dona Noemia e sua busca de constituir-se arteducadora é o fato de ela ter pleiteado uma bolsa de estudos para a Inglaterra. Lá, fez um curso organizado pelo próprio Read. Ela contava esse episódio de sua vida com muito entusiasmo, especialmente quando narrava a palestra de abertura do curso dada pelo próprio Sir Herbert Read, como ela gostava de nomeá-lo, para destacar que Read era o Cavaleiro da Ordem e ele mesmo abriu o curso com uma palestra.

Comentar as respostas de Dona Noemia significa, aqui, um esforço de atribuir sentidos para seus pensares e fazeres, isto é, tentar escutar seus dizeres e propagálos como um legado que nos ensina: a Arteducação é campo de conhecimento inquieto e inquietante, sempre se refazendo e se reconstituindo. Arteducação é campo aberto ao diálogo e, por isso, averso ao pensamento monocultural e colonizador.

A própria Dona Noemia sempre defendeu o pensamento divergente, que podemos interpretar como aquele que parte do respeito ao ponto de vista do Outro, isto é, implica reconhecer a Alteridade. 


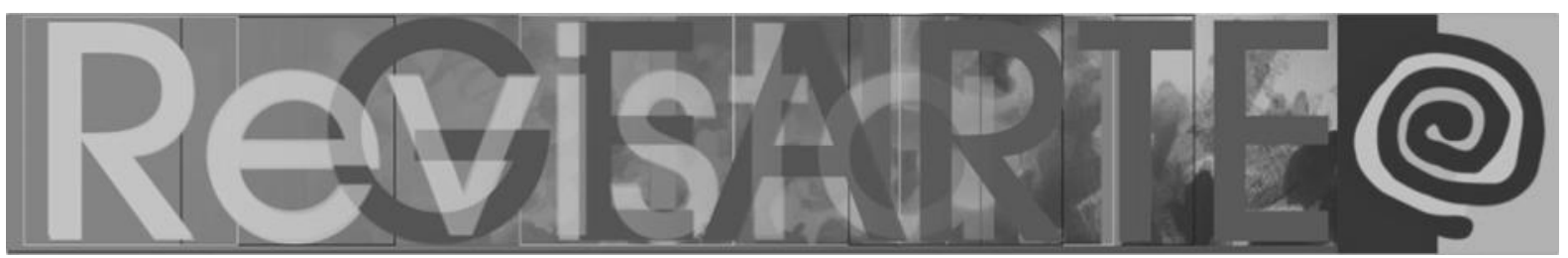

Recife é considerado a cidade do seu coração, por isso, trago, para finalizar o hino do bloco Madeira do Rosarinho, composto por Capiba em 1963.

\section{Madeira que Cupim não Rói}

Madeira do Rosarinho

Vem à cidade sua fama mostrar

E traz com seu pessoal

Seu estandarte tão original

Não vem pra fazer barulho

Vem pra dizer e com satisfação

Queiram ou não queiram os juízes

O nosso bloco é de fato campeão

E se aqui estamos, cantando essa canção

Viemos defender a nossa tradição

E dizer bem alto que a injustiça dói

Nós somos madeiras de lei que cupim não rói

\section{Referências}

ALVES, Flávia Camargo Leal. Escolinha de Arte da UFRGS (1960-2011): história, fundamentos e ressonâncias com o Movimento Escolinhas de Arte. Porto Alegre: UFRGS, 2019. 191 f. Dissertação (Mestrado em Educação) - Programa de Pós-Graduação em Educação, Faculdade de Educação, Universidade Federal do Rio Grande do Sul, Porto Alegre, 2019. Disponível em: https://lume.ufrgs.br/bitstream/handle/10183/189607/001090077.pdf?sequence=1\&isAllowed=y.

Acesso em: 10 jun 2019.

BOSI, Ecléa. O tempo vivo da memória: ensaios de psicologia social. São Paulo: Ateliê Editorial, 2003.

CASTELO BRANCO, Guilherme. Anti-individualismo, vida artista: uma análise não-fascista de Michel Foucault. In: RAGO, Margareth; VEIGA-NETO, Alfredo. (Orgs.). Para uma vida não-fascista. Belo Horizonte: Autêntica, 2009. p. 143-151.

BURKE, Peter. (Org.). A escrita da história: novas perspectivas. São Paulo: UNESP, 2011.

ORLANDI, Eni Puccinelli. A linguagem e seu funcionamento: as formas do discurso. 6. ed. São Paulo: Cortez; Campinas: Editora da Universidade Estadual de Campinas, 2011.

ORLANDI, Eni Puccinelli. Interpretação: autoria, leitura e efeitos do trabalho simbólico. 2. ed. Campinas: Pontes, 2007.

READ, Herbert. Educação pela arte. São Paulo: Martins Fonte, 1982.

SILVA, Franklin Leopoldo. O conhecimento de si. São Paulo: Casa da Palavra, 2011.

\section{Fernando Antônio Gonçalves de Azevedo}

Graduado em Filosofia pela Universidade Católica de Pernambuco. Mestre em Artes pela Universidade de São Paulo e Doutor em Educação pela Universidade Federal de Pernambuco. Professor do curso 


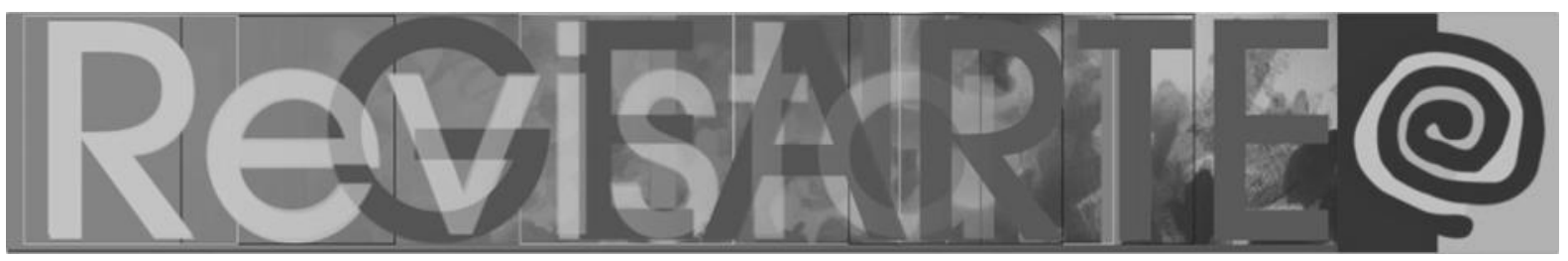

de Pedagogia no Centro Acadêmica do Agreste da Universidade Federal de Pernambuco - UFPE/CAA. Membro do grupo de estudos GEARTE (Grupo de Pesquisa em Educação e Arte) pela Universidade Federal do Rio Grande do Sul. Entre os livros publicados: A Abordagem Triangular no Ensino das Artes como Teoria e a Pesquisa Como Experiência Criadora. Experiência na área de Artes, com ênfase em Ensino de Arte, atuando principalmente nos seguintes temas: arte educação, história da arte educação, educação especial, ensino de arte, formação continuada de professores e inclusão social e cultural, além de Filosofia e Filosofia da Educação.

E-mail: f_azevedo@hotmail.com

Currículo: http://lattes.cnpq.br/6665135954352936

Recebido em 10 de março de 2019 Aceito em 31 de maio de 2019 